\title{
Apoptotic effect of tolfenamic acid on MDA-MB-231 breast cancer cells and xenograft tumors
}

\author{
Hyeong-Jin Kim, ${ }^{1, * *}$ Sung-Dae Cho, ${ }^{2, * *}$ Jin Kim, ${ }^{1}$ So-Jung Kim, ${ }^{1}$ Changsun Choi, ${ }^{3}$ Jong-Suk Kim, ${ }^{4}$ \\ Jeong-Seok Nam, ${ }^{5}$ Ki Han Kwon, ${ }^{6}$ Kyung-Sun Kang $^{7}$ and Ji-Youn Jung ${ }^{1, *}$ \\ 'Department of Companion and Laboratory Animal Science, Kongju National University, Yesan 340-702, Republic of Korea \\ ${ }^{2}$ Department of Oral Pathology, School of Dentistry, Chonbuk National University, Jeonju 561-756, Republic of Korea \\ ${ }^{3}$ Department of Food and Nutrition, College of Human Ecology, Chung-Ang University, Ansung 456-756, Republic of Korea \\ ${ }^{4}$ Department of Biochemistry, Institute of Medical Science, Chonbuk National University Medical School, Jeonju 561-180, Republic of Korea \\ ${ }^{5}$ Lee Gil Ya Cancer and Diabetes Institute, Gachon University of Medicine and Science, Inchon 406-840, Republic of Korea \\ ${ }^{6}$ Department of Food Science and Nutrition, College of Health, Welfare and Education, Gwangju University, Gwangju 503-703, Republic of Korea \\ ${ }^{7}$ Department of Veterinary Public Health, College of Veterinary Medicine, Seoul National University, Seoul 151-742, Republic of Korea
}

(Received 2 August, 2012; Accepted 21 March, 2013; Published online 29 June, 2013)

Recent studies have indicated that non-steroidal anti-inflammatory drug (NSAID), particularly tolfenamic acid, can inhibit proliferation and induce apoptosis invarious cancer cells. Breast cancer represents one-third of all cancers diagnosed in women and is the second leading cause of cancer death in Western European and North American women. In the present study, we investigated the apoptotic effect of tolfenamic acid in MDA-MB-231 estrogen receptor-negative human breast carcinoma cells and in a xenograft tumor model. Treatment of cells with tolfenamic acid significantly decreased cell viability in a concentration-dependent manner. Notably, tolfenamic acid increased apoptosis-related proteins, such as $\mathrm{p} 53$ and p21, within $48 \mathrm{~h}$. Furthermore, in vivo experiments showed that tolfenamic acid treatment resulted in a significant reduction in tumor volume over 5 weeks. Immunohistochemistry results showed that apoptosis-related protein induction by tolfenamic acid was significantly higher in the $50 \mathrm{mg} / \mathrm{kg}$-treated group compared to the control group. Together, these results indicate that tolfenamic acid induces apoptosis in MDA-MB-231 breast cancer cells and tumor xenograft model and it may be a potential chemotherapeutic agent against breast cancer.

Key Words: tolfenamic acid, MDA-MB-231, apoptosis, p53, p21

olfenamic acid (TA) is a non-steroidal anti-inflammatory drug (NSAID) that is related structurally to drugs such as mefenamic acid, flufenamic acid, and meclofenamic acid. The compound has modest anti-inflammatory activity and is mainly used as a short-term analgesic. ${ }^{(1)}$ However, recent studies have indicated that NSAIDs, particularly TA, can inhibit proliferation and induce apoptosis of various cancer cells. ${ }^{(2)}$ For example, in oral cancer cells, TA induces apoptotic cell death and inhibits cancer growth by activating the p38 MAPK pathway. ${ }^{(3)}$ TA also stimulates activating transcription factor 3 (ATF3) expression and subsequently induces apoptosis in colorectal cancer cells. ${ }^{(4)}$ In addition, it inhibits esophageal cancer through repression of specificity proteins and c-Met. ${ }^{(5)}$ These lines of evidence have demonstrated the efficacy of this drug for cancer chemotherapy.

Breast cancer represents one-third of all cancers diagnosed in women and is the second leading cause of cancer death in Western European and North American women. ${ }^{(6)}$ In addition, it is a major cause of premature death in women. ${ }^{(2)}$ However, no report exists concerning the role and molecular basis of TA in apoptosis of human breast cancer cells. Thus, in the present study, we investigated the mechanism of TA-induced apoptosis in MDA-MB-231 estrogen receptor (ER)-negative human breast carcinoma cells and xenograft tumors.

Apoptosis is a physiologically programmed mechanism of cell death that is involved in cellular stress responses; it contributes to the anti-tumor activity of many chemotherapeutic drugs. Induction of apoptosis is not only an important defense against cancer, but has recently drawn attention as a novel target for cancer chemoprevention. ${ }^{(7)}$ One potential molecular target for inducing apoptosis is the tumor suppressor protein p53.(8) It acts as a nuclear transcription factor, binding to DNA to regulate the transcription of p53-regulated genes, and it monitors DNA integrity, preventing the division of genetically damaged cells. Approximately half of all human cancers exhibit inactivating mutations of p53; most others deactivate the p53 pathway by elevating its inhibitors, reducing its activators, or inactivating its downstream targets. Thus, p53 is a central protein in tumorigenesis due to its apoptosisregulating properties. ${ }^{(9)}$

The mitochondrial membrane constitutes the battlefield on which pro- and anti-apoptotic factors induce or prevent a potentially lethal permeabilization step. ${ }^{(10)}$ Under various cell deathinducing conditions, p53 rapidly moves to the mitochondria. Once at the mitochondrion, p53 induces mitochondrial outer membrane permeabilization (MOMP), thereby triggering the release of proapoptotic factors from the mitochondrial intermembrane space. ${ }^{(11)}$ MOMP is usually inhibited by anti-apoptotic multidomain proteins of the Bcl-2 family (such as Bcl-2, Bcl-XL, and Mcl-1), and is conditional on pro-apoptotic multidomain proteins from the same family (in particular Bax and Bak) that can homooligomerize within the outer mitochondrial membrane to form MOMP-mediating supramolecular structures. ${ }^{(11)}$

The main goal of the present study was to determine the mechanism of TA-induced apoptosis in breast cancer cells. The 3-(4,5-dimethylthiazol-2-yl)-2,5-diphenyltetrazolium bromide (MTT) assay was used to measure the survival rate of MDA-MB 231 cells in vitro. To evaluate whether the growth-inhibitory effect of TA was due to apoptotic death, we assayed cells using annexin V/propidium iodide (PI) staining. In addition, we used Western

*To whom correspondence should be addressed.

E-mail: wangza@kongju.ac.kr

**Both authors contributed equally to this paper. 
blot analysis to determine the relevance of each marker in apoptosis. In vivo studies were used to evaluate TA-induced apoptosis. It is not known what effects might occur if TA were administered on the day of tumor implantation. Accordingly, tumor size was measured every 2 days after implantation of a tumor fragment into nude mice for up to 5 weeks, and examined by immunohistochemical (p21, p53) and terminal deoxynucleotidyl transferase dUTP-biotin nick end labeling (TUNEL) assays to detect TAinduced apoptosis.

\section{Materials and Methods}

Chemicals. Dimethyl sulfoxide (DMSO) and TA were purchased from Sigma-Aldrich (St. Louis, MO). RPMI1640, fetal bovine serum (FBS), and trypsin-EDTA solution $(1 \times)$ were purchased from HyClone Laboratories (Logan, UT). Anti-cleaved PARP, anti- $\beta$-actin, anti-Bcl-2, and anti-Bax were purchased from Cell Signaling Biotechnology (Danvers, MA). Anti-p53 and secondary antibodies were purchased from Abcam (Cambridge, England). The TUNEL kit was purchased from Promega (Madison, WI).

Cell culture. ER-negative human breast adenocarcinoma MDA-MB-231 cells were obtained from the Korean Cell Line Bank. MDA-MB-231 cells were maintained in RPMI-1640 supplemented with $10 \% \mathrm{FBS}, 100$ units $/ \mathrm{ml}$ penicillin, and $100 \mu \mathrm{g} / \mathrm{ml}$ streptomycin (HyClone Laboratories) at $37^{\circ} \mathrm{C}$ in a humidified atmosphere with $5 \% \mathrm{CO}_{2}$.

MTT cell viability assay. The effect of TA on the cell viability of MDA-MB-231 cells was determined using the MTT assay. The viability of cultured cells was determined by reduction of MTT (Sigma-Aldrich) to formazan. Briefly, $5 \times 10^{4}$ cells $/$ well were seeded on a 12-well plate, and then treated with TA at various concentrations. After incubation for $48 \mathrm{~h}$, cells were washed twice with phosphate-buffered saline (PBS). MTT (1 mg/ $500 \mu \mathrm{l}$ PBS) was then added to each well, cells were incubated at $37^{\circ} \mathrm{C}$ for $4 \mathrm{~h}$, and DMSO $(1 \mathrm{ml})$ was added to dissolve the formazan crystals. Optical densities of the solutions were determined using a spectrophotometer (Ultrospec 2100 pro; Amersham Biosciences, Uppsala, Sweden) at $570 \mathrm{~nm}$. Cell viability was expressed as the optical density ratio of the treatment to the control.

Western blot assay. Cells were treated with various concentrations of TA for $48 \mathrm{~h}$, and then protein concentrations were determined using the Bradford protein assay (Bio-Rad Laboratories, Hercules, CA). Total proteins $(20 \mu \mathrm{g})$ in each cell lysate were resolved on various concentrations (6-14\%) of sodium dodecyl sulfate-polyacrylamide gel electrophoresis (SDS-PAGE) gels, and then were electro-transferred onto nitrocellulose membranes. The membranes were incubated with blocking buffer $(5 \%$ non-fat dry milk in Tris-buffered saline with Tween 20 (TBS-T)) for $1 \mathrm{~h}$ at room temperature, and then were further incubated with specific antibodies diluted in blocking solution overnight at $4^{\circ} \mathrm{C}$. After washing with TBS-T, membranes were incubated with horseradish peroxidase (HRP)-conjugated secondary antibodies for $1 \mathrm{~h}$ at room temperature. After washing, bands were visualized using enhanced chemiluminescence (ECL) detection reagents (Pierce Biotechnology, Rockford, IL) according to the manufacturer's instructions.

Nuclear morphology. To assess apoptosis, the nuclei of MDA-MB-231 cells were stained with 4',6-diamidino-2phenylindole (DAPI). Cells were seeded on 12-well micro plates at $4 \times 10^{4}$ cells/well, and then were incubated with 0,50 , or $100 \mu \mathrm{M}$ TA for $48 \mathrm{~h}$. After treatment with TA, cells were harvested, washed with PBS, and fixed with $4 \%$ paraformaldehyde in PBS for $20 \mathrm{~min}$ at room temperature. Fixed cells were washed with PBS and stained with $2 \mathrm{ml}$ DAPI solution (1:9 dilution) in the dark for $1 \mathrm{~h}$ at room temperature. Cells were washed twice with PBS, and analyzed under a fluorescent microscope $(\times 400)$.
Annexin V staining for analysis of apoptosis. After stimulation of MDA-MB-231 cells with TA, cell apoptosis was measured using an Annexin $\mathrm{V}$ staining kit (Becton Dickinson, Franklin Lakes, NJ). MDA-MB-231 cells grown in a $25 \mathrm{~cm}^{2}$ flask were collected following mild trypsinization. According to manufacturer's instruction, trypsinized cells were washed once with PBS, and then were resuspended in $100 \mu$ Annexin binding buffer and mixed with $5 \mu$ l fluorescein isothiocyanate (FITC)conjugated Annexin $\mathrm{V}$ and phycoerythrin (PE)-conjugated PI. Resuspended cells were incubated at room temperature in the dark for $15 \mathrm{~min}$. After incubation, $400 \mu \mathrm{l}$ Annexin binding buffer was added. Labeled cells were analyzed by FACSCalibur (Becton Dickinson, Franklin Lakes, NJ).

Breast tumor xenografts. Male athymic nude mice (NCInu) were purchased from Orient BIO Inc. (Gyeonggi-do, Korea). Mice were housed and maintained under specific pathogen-free conditions. Mice were used in accordance with institutional guidelines at ages 8 to 12 weeks. MDA-MB-231 cells $\left(2.5 \times 10^{6} /\right.$ $\mathrm{ml})$ were implanted subcutaneously into the flank of each mouse (two places, $200 \mu \mathrm{l}$ ). Two weeks after cell inoculation, when palpable tumors were observed, mice were randomly assigned to different groups to receive one of the following treatments. The control group received oral administrations of vehicle corn oil. The low-dose group received oral administrations of TA $(25 \mathrm{mg} /$ $\mathrm{kg} / \mathrm{d}$ body weight) in corn oil. The high-dose group received oral administrations of TA $(50 \mathrm{mg} / \mathrm{kg} / \mathrm{d}$ body weight) in corn oil. Treatments were continued for 5 weeks, and then the mice were sacrificed by $\mathrm{CO}_{2}$ asphyxiation, weighed, and subjected to necropsy. The volume and weight of xenograft tumors were recorded. Selected tissues were further examined by routine hematoxylin and eosin (H\&E) staining and immunohistochemical analysis. Mice were monitored for up to 5 weeks after implantation, and the tumor size was measured in two dimensions for every other day starting on day 1 up to 5 weeks with Vernier calipers (Mitutoyo, Kawasaki, Japan) and calculated using the formula $[$ (length + width $) \times 0.5]^{3}$.

TUNEL assay. Paraffin-embedded tumor tissues were used for TUNEL staining, which was performed using the DeadEnd Colorimetric TUNEL system (Promega). Paraffin-embedded sections ( $5 \mu \mathrm{m}$ thick) were processed according to the manufacturer's protocol. Briefly, sections were deparaffinized in xylene, and then treated with a graded series of alcohol $(100 \%, 95 \%$, $85 \%, 70 \%$, and $50 \%$ ethanol $[\mathrm{v} / \mathrm{v}]$ in double-distilled $\left.\mathrm{H}_{2} \mathrm{O}\right)$ and rehydrated in PBS ( $\mathrm{pH} 7.5)$. Then the tissues were treated with proteinase $\mathrm{K}$ solution for permeabilization and refixed with $4 \%$ paraformaldehyde solution. Slides were treated with the rTdT reaction mix and incubated at $37^{\circ} \mathrm{C}$ for $1 \mathrm{~h}$; reactions were terminated by immersing the slides in $2 \times \mathrm{SSC}$ solution for $15 \mathrm{~min}$ at room temperature. After blocking endogenous peroxidase activity (with $0.3 \%$ hydrogen peroxide), slides were washed with PBS, and then incubated with streptavidin-horseradish peroxidase solution for $30 \mathrm{~min}$ at room temperature. After washing, slides were incubated with 3,3-diaminobenzidine (substrate) solution until a light brown background appeared $(10 \mathrm{~min})$, and then rinsed several times in deionized water. Methyl green was used for background staining. After mounting, slides were observed using a light microscope.

Immunohistochemistry. When tumors reached about $5000 \mathrm{~mm}^{3}$ in size, animals were euthanized using an overdose of inhalation anesthesia. For detection of p21 and p53, tumors were excised and fixed in $10 \%$ buffered formalin for 7 days, dehydrated in $50 \%, 70 \%, 95 \%$, and $100 \%$ ethanol, $15 \mathrm{~min}$ each time, and then submerged in xylene twice, 10 min each time. Paraffin-embedded tissue blocks were prepared with a machine (Shandon Embedding Center; Shandon Inc., Pittsburgh, PA) and were cut with a microtome (Shandon Inc.). Next, 5- $\mu$ m-thick sections were placed on glass slides and stretched on a slide heating plate at $43^{\circ} \mathrm{C}$. The glass slides were incubated in a paraffin 
oven at $37^{\circ} \mathrm{C}$ for 1 day. The sections were deparaffinized with two changes of xylene, $10 \mathrm{~min}$ each time, rehydrated with two changes each of $100 \%$ ethanol and $95 \%$ ethanol for $1 \mathrm{~min}$, and then rinsed with tap water for $10 \mathrm{~min}$. Sections were incubated at $4^{\circ} \mathrm{C}$ with anti-p21 (Cell Signaling Technology) and anti-p53 (Abcam) overnight, and then incubated for $1 \mathrm{~h}$ at room temperature with a peroxidase-conjugated goat anti-mouse antibody, followed by incubation for $1 \mathrm{~h}$. Subsequently, sections were stained with methyl green, and then sections on glass slides were treated with a mounting reagent $(\mathrm{O}$. Kindler $\mathrm{GmbH}$, Freiburg, Germany) and observed under a microscope.

Statistical analysis. All data are expressed as means $\pm \mathrm{SE}$. One-way analysis of variance (ANOVA) was used to analyze statistical differences among multiple comparisons. A value of $p<0.05$ was considered to be statistically significant.

\section{Results}

To test the effects of TA on proliferation of MDA-MB-231 cells, we treated cells with various concentrations of TA $(0,50$, or $100 \mu \mathrm{M}$ ) for 24 or $48 \mathrm{~h}$ and analyzed the surviving cells using MTT assay. As shown in Fig. 1B, TA induced cell death in a concentration- and time-dependent manner. Treatment with $100 \mu \mathrm{M}$ TA for 24 or $48 \mathrm{~h}$ resulted in significant decreases in cell viability compared to the control group $(p<0.05)$.

To evaluate the effects of TA on chromatin condensation, we treated MDA-MB-231 cells with 50 or $100 \mu \mathrm{M}$ TA for $48 \mathrm{~h}$ and examined them for apoptosis using DAPI staining, which distinguishes live from apoptotic cells based on nuclear morphology. The presence of chromatin condensation in TA-treated cells was detected on a fluorescence microscope $(\times 400)$. DAPI forms
A<smiles>Cc1c(Cl)cccc1Nc1ccccc1C(=O)O</smiles>

C

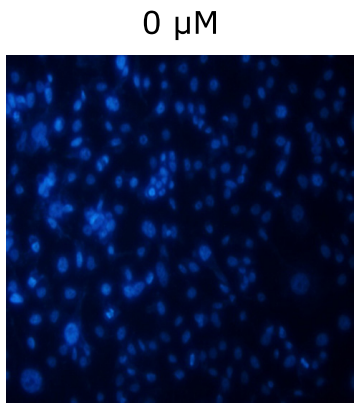

D

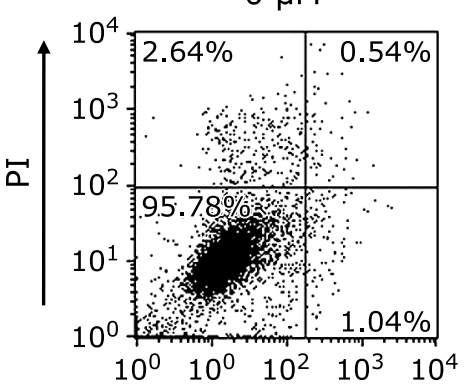

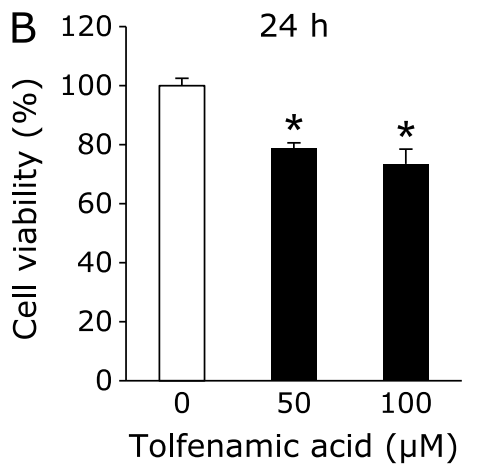

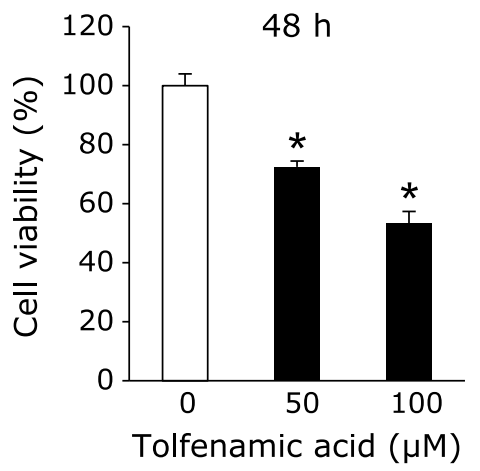

Tolfenamic acid $(\mu \mathrm{M})$
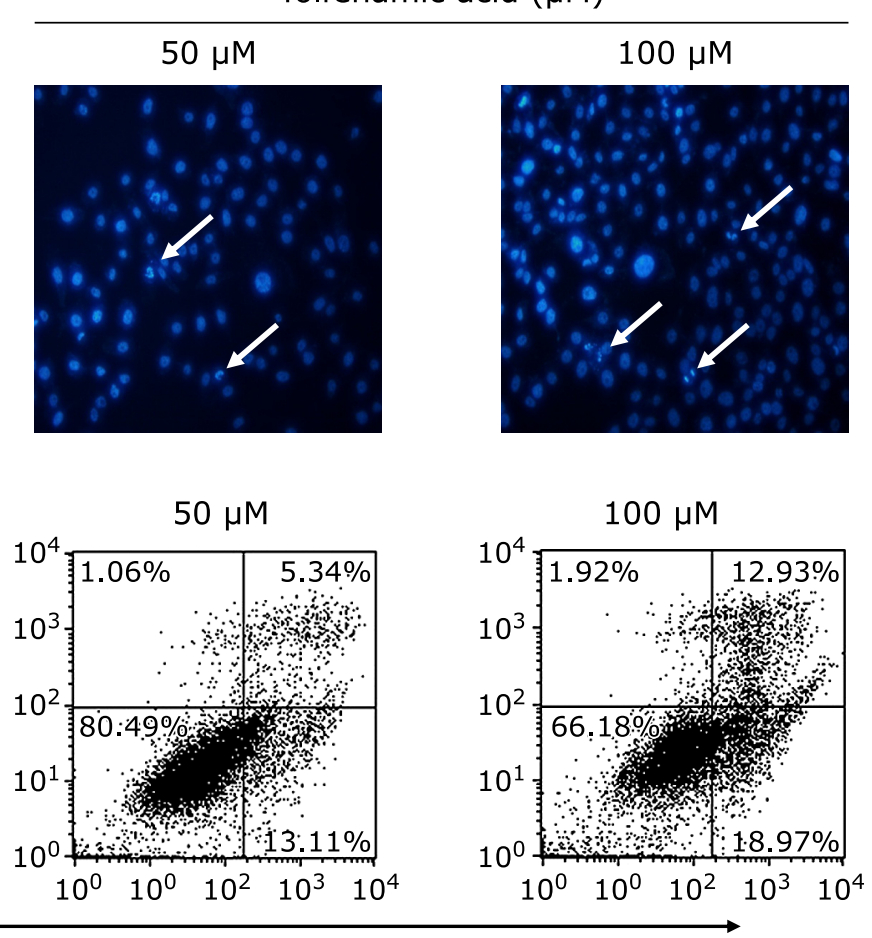

Annexin V-FITC

Fig. 1. Effect of tolfenamic acid on viability and annexin-positive apoptotic cells. (A) Structure of naturally occurring tolfenamic acid. (B) MDA-MB231 cells were treated with tolfenamic acid $(0,50$, or $100 \mu \mathrm{M})$ for 24 or $48 \mathrm{~h}$, and cell viability was determined using the 3-(4,5-dimethylthiazol-2-yl)2,5-diphenyltetrazolium bromide (MTT) assay as described in Materials and Methods. Each bar represents the mean \pm SE of three separate experiments, and data are expressed as the percent relative to the control. ${ }^{*} p<0.05$ significantly different compared with the control group. (C) MDA-MB231 cells were treated with 0,50 , or $100 \mu \mathrm{M}$ tolfenamic acid for $48 \mathrm{~h}$ and stained with 4',6-diamidino-2-phenylindole (DAPI). Chromatin condensation, representing apoptotic cell death, was examined using a fluorescence microscope $(\times 400)$. (D) Cells were treated with tolfenamic acid $(0,50$, or $100 \mu \mathrm{M}$ ) for $48 \mathrm{~h}$. Cells positive for either annexin $\mathrm{V}$ or both annexin $\mathrm{V}$ and propidium (PI) were considered to be early apoptotic and late apoptotic cells, respectively. Labeled cells were analyzed by FACS analysis. The figure shows a representative staining profile for 10,000 cells per experiment. 
fluorescent complexes with double-I banded DNA, and stained nuclei show a bright fluorescence with a DAPI filter. As shown in Fig. $1 \mathrm{C}$, cells treated with $100 \mu \mathrm{M}$ TA fluoresced brightly, indicating chromatin condensation. To further understand whether TA-induced cell death is mediated by apoptosis or necrosis, we evaluated apoptotic cell death using annexin V/PI double staining, which specifically labels apoptotic cells. As shown in Fig. 1D, treatment with TA at concentrations of 50 and $100 \mu \mathrm{M}$ for $48 \mathrm{~h}$ induced apoptosis in $18.45 \%$ and $31.90 \%$ of the cells, respectively.

To confirm whether p53 protein was related to TA-induced apoptosis, we treated MDA-MB-231 cells with various concentrations of TA $(0,25,50,75,100 \mu \mathrm{M})$ for $48 \mathrm{~h}$ and analyzed apoptosis-related proteins using Western blotting. As shown in Fig. 2A, p53 increased in a dose-dependent manner. In cells treated with $100 \mu \mathrm{M}$ TA, p53 protein was significantly increased after $48 \mathrm{~h}$, and up-regulation of p21 was also observed. As shown in Fig. 2B, to determine the effect on apoptosis-related proteins in TA-treated MDA-MB-231 breast tumors, we administered TA $(0,25$, or $50 \mathrm{mg} / \mathrm{kg})$ to three groups of five mice each for 5 weeks. When the control group tumors reached about $1000 \mathrm{~mm}^{3}$ in size, the animals were sacrificed and $5 \mu \mathrm{m}$ sections were prepared. The expression of p53 was significantly greater in the $50 \mathrm{mg} / \mathrm{kg}$ treated group than in the control group (Fig. 2B, upper panel). Similar results were observed for p21 (Fig. 2B, under panel). In contrast, no significant change was apparent in non-treated control cells after $48 \mathrm{~h}$.

The expressions of p53 downstream effectors such as Bax and Bcl-2 are critical for cell cycle arrest and apoptotic death. As shown in Fig. 3, Bcl-2 protein decreased, and Bax protein increased in TA-treated cells. In addition, a marked increase in
A

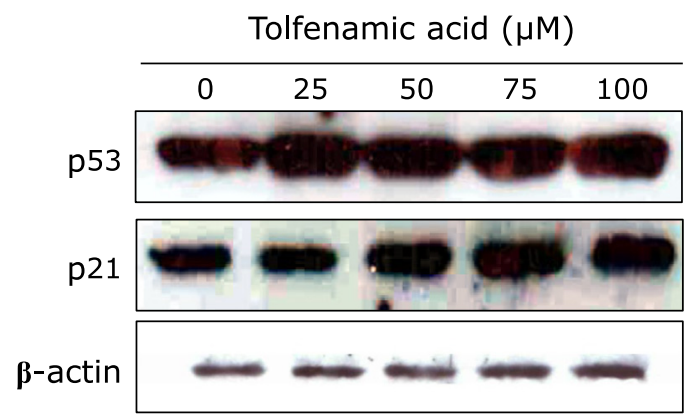

B

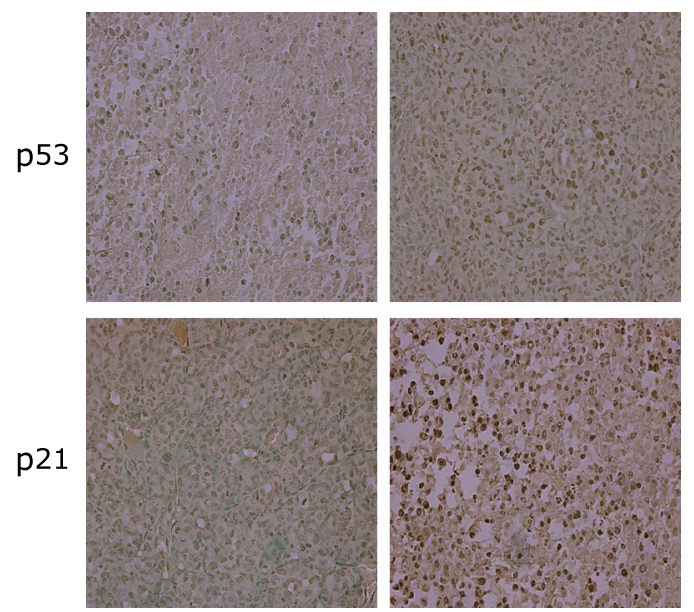

Fig. 2. Effect of tolfenamic acid on p53 and p21 expression in MDA-MB-231 breast tumors. (A) Cells were treated with tolfenamic acid (0, 50 , or $100 \mu \mathrm{M})$ for $48 \mathrm{~h}$. Cell lysates were prepared as described in Materials and Methods and analyzed by $12 \%$ SDS-PAGE followed by Western blot analysis. The membranes were incubated with anti-p53 and anti-p21 overnight. The blots were also probed with anti- $\beta$-actin to confirm equal loading of samples. (B) Nude mice were administered tolfenamic acid (0,25, or $50 \mathrm{mg} / \mathrm{kg}$ ) for 5 weeks and assayed by immunohistochemistry using p53 and p21 antibodies. Slides were observed under a microscope and photographed ( $\times 400)$. Paraffin-embedded tumors were sectioned (5 $\mu \mathrm{m})$.

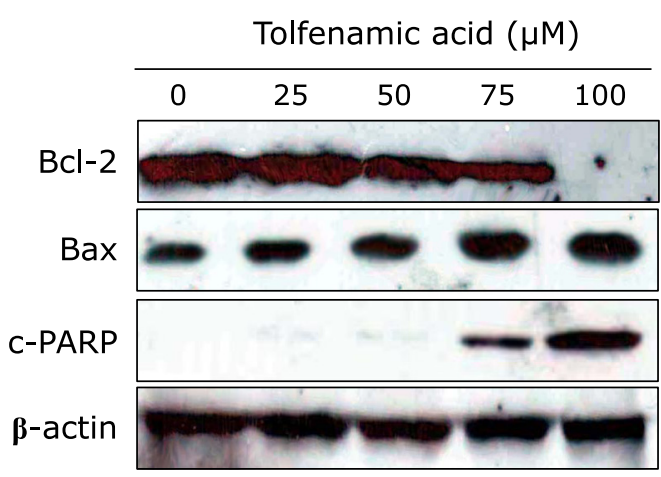

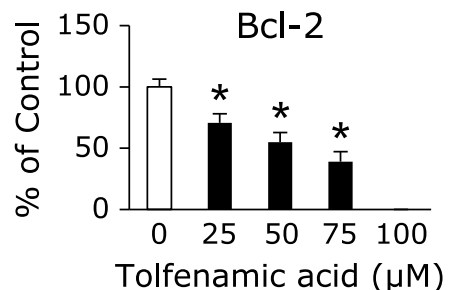
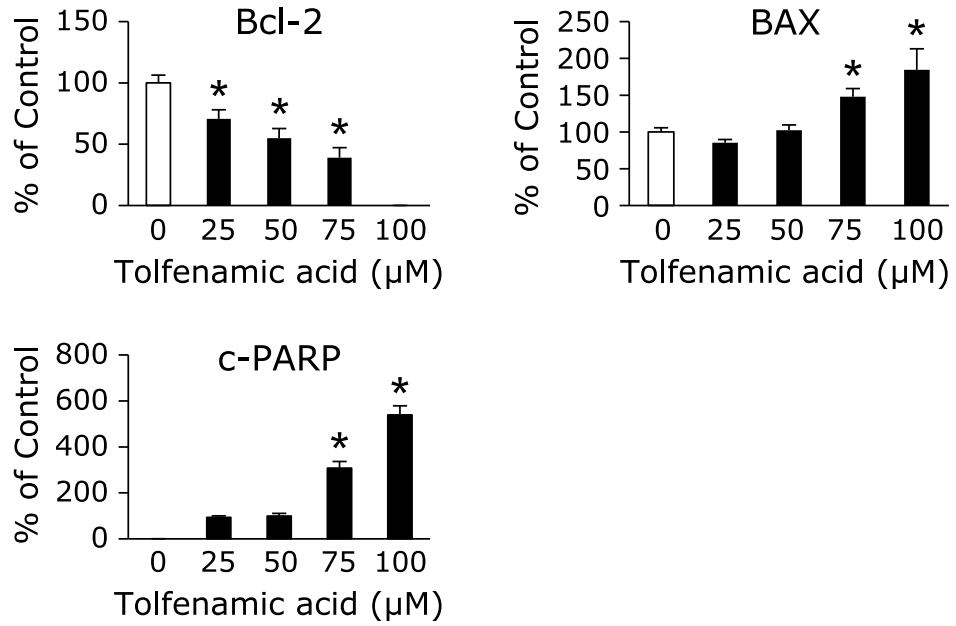

Fig. 3. Effect of tolfenamic acid on p53. Cells were treated with tolfenamic acid $(0,50$, or $100 \mu \mathrm{M})$ for $48 \mathrm{~h}$. Cell lysates were prepared as described in Materials and Methods and analyzed by $12 \%$ SDS-PAGE followed by Western blot analysis. The membranes were incubated with anti-Bax, anti$\mathrm{Bcl}-2$, anti-cleaved PARP, and anti-caspase-3. The blots were also probed with anti- $\beta$-actin to confirm equal loading of samples. Each graph represents the mean \pm SE of three separate experiments, and data are expressed as percent relative to the control. ${ }^{*} p<0.05$ significantly different compared with the control group. 

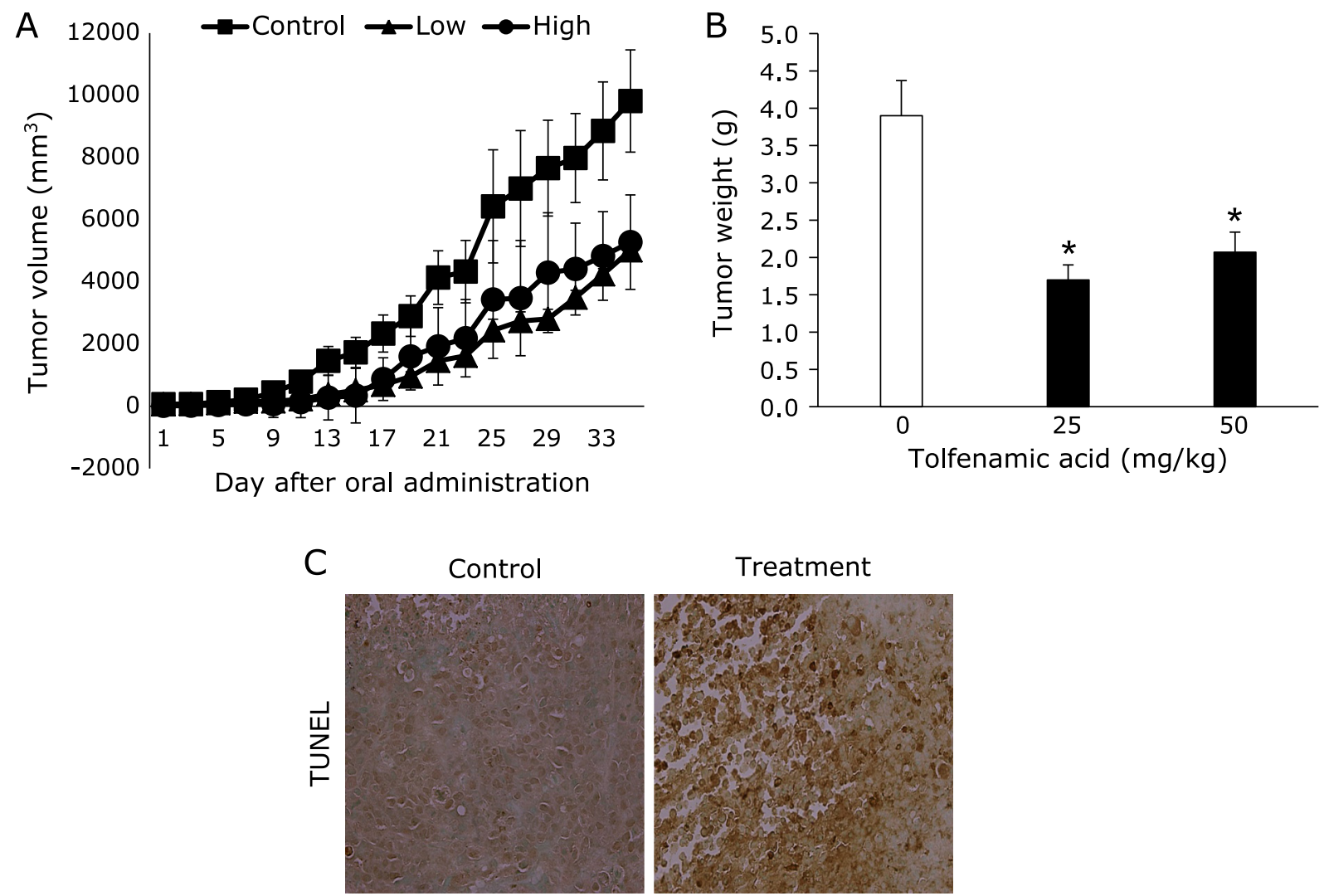

Fig. 4. Effect of tolfenamic acid on MDA-MB-231 breast tumor growth and apoptosis. (A) To assess the effects of tolfenamic acid on MDA-MB-231 breast tumor growth, mice were treated with tolfenamic acid $(0,25$, or $50 \mathrm{mg} / \mathrm{kg}$ ) for 35 days and tumors were measured using Vernier calipers. (B) Final tumor weights. Each value represents the mean \pm SE for five mice. ${ }^{*} p<0.05$ significantly different compared with the control group. (C) Nude mice were administered tolfenamic acid $(0,25$, or $50 \mathrm{mg} / \mathrm{kg})$ for 5 weeks and subject to the TUNEL assay as described in Materials and Methods. Slides were observed under a microscope and photographed $(\times 400)$. Paraffin-embedded tumors were sectioned $(5 \mu \mathrm{m})$.

Table 1. Effect of tolfenamic acid on tumor inhibition rate in MBA-MB231 human breast cancer

\begin{tabular}{|c|c|c|c|c|c|}
\hline \multirow{2}{*}{ Groups } & \multicolumn{2}{|c|}{ Pre-experiment } & \multicolumn{2}{|c|}{ Post-experiment } & \multirow{2}{*}{$\begin{array}{l}\text { Inhibition } \\
\text { Rate (\%) }\end{array}$} \\
\hline & $n$ & Size $\left(\mathrm{mm}^{3}\right)$ & $n$ & Size $\left(\mathrm{mm}^{3}\right)$ & \\
\hline $0 \mathrm{mg} / \mathrm{kg}$ & 5 & 66.95 & 5 & 9814.43 & \\
\hline $25 \mathrm{mg} / \mathrm{kg}$ & 5 & 62.2 & 5 & 5014.82 & 48.9 \\
\hline $50 \mathrm{mg} / \mathrm{kg}$ & 5 & 100.23 & 5 & 5277.13 & 46.23 \\
\hline
\end{tabular}

Data are expressed as the percent relative to the control.

cleaved PARP was observed in TA-treated cells. These results indicate that TA-induced apoptosis might be related to $\mathrm{p} 53$ and its downstreams.

To assess the effects of TA on MDA-MB-231 breast tumor growth, we measured tumor size every 2 days after implantation into mice for up to 5 weeks. As described in Fig. 4A, tumor volume was significantly decreased in the 25 and $50 \mathrm{mg} / \mathrm{kg}$ TAtreated groups compared to the control group $(p<0.05)$. TA also inhibited tumor weight in MDA-MB-231 cell xenografts (Fig. 4B). As shown in Table 1 , the groups that were given TA showed a significant reduction in tumor volume at day 35 , down to $48.90 \%$ in the $25 \mathrm{mg} / \mathrm{kg}$ group and $46.23 \%$ in the $50 \mathrm{mg} / \mathrm{kg}$ group compared to the control group $(0 \mathrm{mg} / \mathrm{kg} ; p<0.05$ for both). As shown in Fig. 4C, a significant increase in TUNEL-positive cells was observed in the $50 \mathrm{mg} / \mathrm{kg}$-treated group compared to the control group $(p<0.05)$. These in vivo findings support the in vitro findings that TA increases apoptosis in MDA-MB-231 breast tumor cells.

\section{Discussion}

We demonstrated the effects of TA on apoptosis in MDA-MB231 ER-negative human breast cancer cells. ER-negative breast cancer cells are known to have highly tumorigenic, invasive, metastatic, and proliferative characteristics and to respond less to current anticancer agents. ${ }^{(12)}$

To test the effect of TA on proliferation of MDA-MB-231 cells, we performed the MTT assay. As shown in Fig. 1B, TA significantly decreased MDA-MB-231 cell viability in a dose-dependent manner. It has similar effects on neuroblastoma, ovarian, mucoepidermoid, and colorectal cancer cells. ${ }^{(13-16)}$ To further understand whether this TA-induced inhibition of cell viability is due to apoptosis, we performed annexin V and PI double staining assays. As shown in Fig. 1D, treatment of TA at concentrations of 50 and $100 \mu \mathrm{M}$ for $48 \mathrm{~h}$ induced apoptosis in $18.45 \%$ and $31.90 \%$ of the cells, respectively. However, only $1.92 \%$ of the total cell population showed necrotic cell death. These results indicate that the cytotoxicity caused by TA is mediated by apoptosis.

Apoptosis is the result of a highly complex cascade of cellular events characterized by chromatin condensation, DNA fragmentation, and cell shrinkage. ${ }^{(17,18)}$ To evaluate the effect of TA on chromatin condensation, we performed DAPI staining. DAPI forms fluorescent complexes with double-stranded DNA, and stained nuclei brightly fluoresce under a DAPI filter. As shown in Fig. $1 \mathrm{C}$, cells treated with $100 \mu \mathrm{M}$ TA fluoresced brightly, indicating chromatin condensation.

To confirm whether the p53 protein may be associated with TA-induced apoptosis, we performed Western blot assays. As 
shown in Fig. 2A, p53 was induced following TA treatment. It has also been shown to be associated with up-regulation of proapoptotic Bax. ${ }^{(19,20)}$ Pro-apoptotic Bax is one of the direct targets of p53, an apoptotic protein, and Bcl-2, an anti-apoptotic protein. ${ }^{(21)}$ Mitochondria-mediated apoptosis is regulated by the Bcl-2 family of proteins, which can promote (pro-apoptotic Bax members) or inhibit (anti-apoptotic Bcl-2 members) apoptosis. Bcl-2 preserves the integrity of the outer mitochondrial membranes and thereby prevents the release of pro-apoptotic factors from mitochondria. Although the effects of Bcl-2 on the release of pro-apoptotic factor are well described, other functions of Bcl-2 in the upstream and downstream regulation of apoptosis remain poorly understood. Bcl-2 seems to inhibit many agent-induced apoptosis through inactivation of caspase- 3 . Western blot analysis revealed that TA increased Bax levels and reduced the total levels of $\mathrm{Bcl}-2$ protein in MDA-MB-231 cells (Fig. 3).

The purpose of our in vivo experiments was to examine the mechanism of TA-induced apoptosis via p53-dependent apoptotic cell death in nude mice. To assess the effects of TA in reducing MDA-MB-231 breast tumor volume, we administered TA $(0,25$, or $50 \mathrm{mg} / \mathrm{kg}$ ) to three groups of five mice each for 5 weeks. As shown in Fig. 4A, the groups that were administered TA showed a

\section{References}

1 Kim YB, Chung UT, Park IY. The crystal structure of tolfenamic acid $\left(\mathrm{C}_{14} \mathrm{H}_{12} \mathrm{CINO}_{2}\right)$, an antiinflammatory fenamate. Arch Pharm Res 1996; 19: $160-162$.

2 Liu X, Abdelrahim M, Abudayyeh A, Lei P, Safe S. The nonsteroidal antiinflammatory drug tolfenamic acid inhibits BT474 and SKBR3 breast cancer cell and tumor growth by repressing erbB2 expression. Mol Cancer Ther 2009; 8: 1207-1217.

3 Kim JH, Jung JY, Shim JH, et al. Apoptotic effect of tolfenamic acid in KB human oral cancer cells: possible involvement of the p38 MAPK pathway. $J$ Clin Biochem Nutr 2010; 47: 74-80.

4 Lee SH, Bahn JH, Whitlock NC, Baek SJ. Activating transcription factor 2 (ATF2) controls tolfenamic acid-induced ATF3 expression via MAP kinase pathways. Oncogene 2010; 29: 5182-5192.

5 Papineni S, Chintharlapalli S, Abdelrahim M, et al. Tolfenamic acid inhibits esophageal cancer through repression of specificity proteins and c-Met. Carcinogenesis 2009; 30: 1193-1201.

6 Soto-Cerrato V, Llagostera E, Montaner B, Scheffer GL, Perez-Tomas R. Mitochondria-mediated apoptosis operating irrespective of multidrug resistance in breast cancer cells by the anticancer agent prodigiosin. Biochem Phamacol 2004; 68: 1345-1352.

7 Sun SY, Haij N Jr, Lotan R. Apoptosis as a novel target for cancer chemoprevention. J Natl Cancer Inst 2004; 96: 662-672.

8 Green DR, Kroemer G. Cytoplasmic functions of the tumour suppressor p53. Nature 2009; 30: 1127-1130.

9 Riley T, Sontag E, Chen P, Levine A. Transcriptional control of human p53regulated genes. Nat Rev Mol Cell Biol 2009; 9: 402-412.

10 Kroemer G, Galluzzi L, Brenner C. Mitochondrial membrane permeabilization in cell death. Physiol Rev 2007; 87: 99-163.

11 Moll UM, Marchenko N, Zhang XK. p53 and Nur77/TR3 - transcription factors that directly target mitochondria for cell death induction. Oncogene 2006; 25: 4725-4743.

12 Nigam M, Ranjan V, Srivastava S, Sharma R, Balapure AK. Centchroman significant reduction in tumor volume at day 35 , down to $48.90 \%$ in the $25 \mathrm{mg} / \mathrm{kg}$ group and $46.23 \%$ in the $50 \mathrm{mg} / \mathrm{kg}$ group compared to the control group $(0 \mathrm{mg} / \mathrm{kg} ; p<0.05$ for both). TA significantly decreased tumor weights (Fig. 4B). Inhibition of cell proliferation and induction of apoptosis in tumors are effective ways to decrease tumor growth, and p53 is a well-known transcription factor that can modulate the apoptotic process and is involved in the anti-cancer activity of most anti-cancer agents. ${ }^{(22)}$

We found that apoptosis-related protein induction by TA was significantly greater in tissues in the $50 \mathrm{mg} / \mathrm{kg}$-treated group than in the control group (Fig. 2B), and an increase in TUNEL-positive cells was found in the $50 \mathrm{mg} / \mathrm{kg}$-treated tumors compared to the control tumors (Fig. 4C). The control group did not show induction of apoptosis in MDA-MB-231 breast cancer tissues. These in vivo results support the in vitro results and suggest that TA induces apoptotic cell death in MDA-MB-231 breast tumor cells. Together, these results indicate that TA may be a potential chemotherapeutic agent against breast cancer.

\section{Conflict of Interest}

No potential conflicts of interest were disclosed.

induces G0/G1 arrest and caspase-dependent apoptosis involving mitochondrial membrane depolarization in MCF-7 and MDA-MB-231 human breast cancer cells. Life Sci 2008; 82: 577-590.

13 Eslin D, Sankpal UT, Lee C, et al. Tolfenamic acid inhibits neuroblastoma cell proliferation and induces apoptosis: a novel therapeutic agent for neuroblastoma. Mol Carcinog 2011; 28: 215-228.

14 Basha R, Ingersoll SB, Sankpal UT, et al. Tolfenamic acid inhibits ovarian cancer cell growth and decreases the expression of c-Met and survivin through suppressing specificity protein transcription factors. Gynecol Oncol 2011; 122: 163-170.

15 Choi KH, Shim JH, Huong LD, Cho NP, Cho SD. Inhibition of myeloid cell leukemia-1 by tolfenamic acid induces apoptosis in mucoepidermoid carcinoma. Oral Dis 2011; 17: 469-475.

16 Lee $\mathrm{SH}$, Bahn JH, Choi CK, et al. ESE-1/EGR-1 pathway plays a role in tolfenamic acid-induced apoptosis in colorectal cancer cells. Mol Cancer Ther 2008; 7: 3739-3750.

17 Allen RT, Hunter WJ 3rd, Agrawal DK. Morphological and biochemical characterization and analysis of apoptosis. J Pharmacol Toxicol Methods 1997; 37: 215-228.

18 Benson RS, Heer S, Dive C, Watson AJ. Characterization of cell volume loss in CEM-C7A cells during dexamethasone-induced apoptosis. Am J Physiol 1996; 270: C1190-C1203.

19 Oda K, Arakawa H, Tanaka T, et al. p53AIP1, a potential mediator of p53dependent apoptosis, and its regulation by Ser-46-phosphorylated p53. Cell 2000; 102: 849-862.

20 Matsuda K, Yoshida K, Taya Y, Nakamura K, Nakamura Y, Arakawa H. p53AIP1 regulates the mitochondrial apoptotic pathway. Cancer Res 2002; 62: 2883-2889.

21 Prives C, Hall PA. The p53 pathway. J Pathol 1999; 187: 112-126.

22 Fridman JS, Lowe SW. Control of apoptosis by p53. Oncogene 2003; 22: 9030-9040. 